\title{
ОПРЕДЕЛЕНИЕ ФАКТОРОВ, ВЛИЯЮЩИХ НА ВЫБОР ПЕРЕВОЗОК ГРУЗОВ ЖЕЛЕЗНОДОРОЖНЫМ ТРАНСПОРТОМ
}

\author{
(c) 2020 Налбандян Г. Г. \\ старший преподаватель Департамента менеджмента и инноваций \\ Факультета «Высшая школа управления» \\ Финансовый университет при Правительстве Российской Федерации, Россия, Москва \\ E-mail: ggnalbandyan@fa.ru \\ (c) 2020 Ховалова Т.B. \\ старший преподаватель Департамента менеджмента и инноваций \\ Факультета «Высшая школа управления» \\ Финансовый университет при Правительстве Российской Федерации, Россия, Москва \\ E-mail: tvkhovalova@fa.ru
}

В данной статье мы на основе анализа зарубежной и отечественной литературы, а также проведенного опроса экспертов и руководителей компаний выявили факторы, способствующие выбору контейнерных перевозок железнодорожным транспортом. Далее на основе построения эконометрической модели, эмпирически было доказано влияние выявленных факторов на выбор перевозок железнодорожным транспортом.

Ключевые слова: контейнерные перевозки, факторы роста грузопотоков железнодорожным транспортом.

Сложность современного процесса принятия логистических решений ставит перед разработчиками моделей спроса на грузовые перевозки серьезную задачу обеспечить надежные аналитические инструменты как для регулирующих органов, так и для перевозчиков. Это объясняется прежде всего тем, что многие лица, принимающие решения, вовлечены в многопродуктовую и мультимодальную сеть с большим количеством ограничений. Степень теоретической проработки вопроса крайне низкая, что объясняется преимущественно отсутствием эмпирических данных.

Степень влияния характеристик груза на решение о выборе способа перевозки в литературе различна. Feo, Espino and Garcia (2011) обнаружили, что атрибуты вида транспорта оценивались по-разному в зависимости от типа перевозимого груза. В исследовании Nam (1997) была предпринята попытка объяснить различия в поведении грузоотправителей путем дезагрегирования различных товарных групп, включая текстиль, бумагу, химическую продукцию, керамику, основные металлы и электрическую посуду. В ходе исследования было установлено, что между товарными группами существует незначительная дисперсия с точки зрения типов

переменных и их значимости. Потенциальная причина этого, возможно, заключалась в том, что товарные группы и, следовательно, их характеристики не были достаточно разнообразны, чтобы оказывать влияние на поведение при выборе способа перевозки.

Технически большинство грузов, за исключением негабаритных, самоходных и буксируемых машин, например тех, которые используются для добычи полезных ископаемых, дорожного строительства, железнодорожной техники, автобусов и грузовых автомобилей, могут перевозиться в контейнерах. Тем не менее, с точки зрения экономической целесообразности транспортно-логистических операций нецелесообразно перевозить многие малотоннажные, крупнотоннажные грузы в контейнерах. Большинство таких грузов не перевозится в контейнерах. В будущем контейнеры вполне могут быть использованы для перевозки грузов из определенных товарных групп, для которых данный вид транспорта в настоящее время не является первым выбором. Такие обстоятельства могут возникнуть в случае значительного повышения мировых цен на значительную часть продукции, входящей в состав таких групп.

По ряду объективных и субъективных при- 
чин большинство грузовых перевозок между европейскими странами и Китаем в настоящее время осуществляется морским транспортом, причем большинство грузов перевозится в обоих направлениях в контейнерах. Для некоторых из этих грузов, особенно с высокой удельной стоимостью, одним из важнейших конкурентных факторов является время доставки, и технически невозможно сократить это время, если используется морской транспорт. Исходя из таможенной стоимости единицы массы, потребительских свойств товара и технических аспектов упаковки, транспортировки и логистики, продукция машиностроения, за исключением негабаритных машин, не пригодных для контейнерных перевозок, и товары народного потребления (одежда, обувь и др.) являются товарными группами, для которых транзитная доставка через Россию и другие государства-члены ЕАЭС железнодорожным транспортом является оптимальной. Другие группы товаров, которые могут быть переведены с морских перевозок на железнодорожные, включают фармацевтическую продукцию, парфюмерию и косметику, игрушки и спортивное оборудование, а также произведения искусства. Кроме того, исходя из их стоимостных показателей и технических параметров, связанных с перевозкой железнодорожным транспортом в контейнерах, некоторые цветные металлы, такие как дорогостоящая никелевая продукция, также могут эффективно перевозиться в контейнерах.

Расстояние также оказывает сильное влияние на выбор режима (Reis, 2014; Samimi et al., 2011; Brooks et al., 2012). В целом, на коротких расстояниях железнодорожные и морские перевозки не конкурируют с автомобильными перевозками. На коротких маршрутах главное преимущество, которое железная дорога и море имеют над автомобильными перевозками, стоимость, сводится на нет коротким расстоянием. Это связано с тем, что железнодорожные и морские перевозки начинаются с более высокой начальной стоимости из-за интермодальных издержек, однако по мере увеличения расстояния разница в затратах уменьшается. Эти способы также имеют временной недостаток на более коротких расстояниях: необходимо больше времени для загрузки/разгрузки и это составляет гораздо большую долю от общего времени на коротких расстояниях.

\section{Эмпирическая база исследования}

Данное исследование основано на анализе российских компаний, являющихся грузоотправителями. Методом сбора информация был выбран опрос менеджеров, которые несут ответственность за своевременную доставку груза контрагентам. Для реализации цели исследования применен последовательный подход оценки факторов, влияющих на выбор транспорта, состоящий из двух этапов: качественного и количественного.

Качественный этап исследования: предполагал проведение глубинных интервью с экспертами, которые являются представителями компаний грузоотправителей. В рамках предварительного тестирования вопросов анкеты были проведены 6 интервью с менеджерами компаний грузоотправителей, являющиеся представителями российского и зарубежного рынка. Вопросы интервью были направлены на изучение особенностей выбора способа отправки грузов, факторов, способствующих выбору контейнерных перевозок железнодорожным транспортом. Интервью проводилось с помощью Skype для бизнеса, его продолжительность составляла от 20 до 30 минут.

Количественный этап исследования: с помощью рассылки электронных анкет был проведен опрос представителей компаний - отправителей грузов. Респонденты были выбраны из числа менеджеров, представлявших высшее руководство или имеющие наибольшую информированность о выборе способа доставки грузов потребителям. Анкеты были разосланы 138 компаниям - грузоотправителям, представляющим различные отрасли: промышленность, производство строительных материалов, добыча полезных ископаемых, оптовая торговля. Ответы были получены от 43 компаний, отклик составил $31,1 \%$, что считается хорошим результатом. Вместе с тем 43 компании является недостаточным размером выборки, поэтому дополнительно были разосланы анкеты еще 72 компаниям. Ответы получены от 26 компаний, отклик $-36,1 \%$. Итоговая выборка составила 69 компаний. Данная выборка является достаточной для построения регрессионного уравнения.

Проведенный анализ существующей литературы выделяет восемь групп факторов, влияющих на выбор отправки грузов: уровни тарифов, срок доставки, регулярность доставки, точность 
доставки, уровень доверия со стороны грузоотправителей, наличие приборов системы навигации на транспортном средстве, территория, по которой будет осуществляться доставка контейнера, вид груза.

Вместе с тем, проведенное нами интервьюирование позволяет дополнить их еще рядом факторов, определяющих выбор компаниями способа доставки грузов потребителям.

Инфраструктурные факторы. Большинство из опрошенных руководителей компаний (4 из 6) отметили инфраструктурный фактор как барьер для выбора железнодорожных перевозок, т.к. неоптимальное расположение и низкая эффективность контейнерных терминалов снижают скорость доставки товаров, что может негативно сказаться на договорных отношениях.

Экономические факторы. 5 из 6 руководителей компаний - грузоотправителей считают важным фактором достаточно высокий и негибкий тариф контейнерных перевозок, а также повышенные сборы за перевозку в спец. контейнерах.

Технологические факторы. 3 респондента из 6 считают одним из важных факторов низкую скорость железнодорожных контейнерных перевозок вне контейнерного поезда относительно автомобильных и отсутствие регулярности поездов. Кроме того, 2 из 6 руководителей отме- тили низкое качество сервиса, включая неудобство организации контейнерных перевозок по железной дороге.

Регуляторные и административные факторы. 4 респондента из 6 отметили важными факторы длительности таможенных процедур, дублирование процедуры взвешивания контейнеров при погрузке на железнодорожный транспорт, отсутствие сквозного коносамента на мультимодальную перевозку, ограничения по товарному соседству в термических контейнерах, ограничение на хождение контейнеров морских линий внутри РФ.

Далее был проведен корреляционный анализ с целью отбора наиболее значимых факторов из исходного набора путем отсева показателей, имеющих как низкую взаимную корреляцию, так и высокую дискриминирующую силу по зависимой переменной. В Таблице 1 представлены значения парных корреляций факторов, влияющих на выбор компаниями способа перевозки, где в каждом столбце градиентом от светло - зеленого к темному показано возрастание модуля корреляции.

Итогом корреляционного анализа стал набор из 6 показателей, отражающих наиболее сильное влияние факторов на склонность компании к выбору способа перевозки контейнеров. Результаты факторного анализа применялись для

Таблица 1. Модули корреляционных матриц отобранных факторов, влияющих на выбор компаниями способа перевозки контейнеров

\begin{tabular}{|c|c|c|c|c|c|c|c|c|c|c|c|c|c|c|}
\hline Фактор & $\Phi 1$ & $\Phi 2$ & $\Phi 3$ & $\Phi 4$ & $\Phi 5$ & $\Phi 9$ & $\Phi 10$ & $\Phi 11$ & $\Phi 12$ & $\Phi 13$ & $\Phi 15$ & $\Phi 18$ & $\Phi 20$ & $\Phi 24$ \\
\hline$\Phi 1$ & 1 & & & & & & & & & & & & & \\
\hline$\Phi 2$ & 0,032 & 1 & & & & & & & & & & & & \\
\hline$\Phi 3$ & 0,021 & 0,045 & 1 & & & & & & & & & & & \\
\hline$\Phi 4$ & 0,056 & 0,042 & 0,051 & 1 & & & & & & & & & & \\
\hline$\Phi 5$ & 0,034 & 0,057 & 0,065 & 0,037 & 1 & & & & & & & & & \\
\hline$\Phi 9$ & 0,047 & 0,168 & 0,171 & 0,035 & 0,267 & 1 & & & & & & & & \\
\hline$\Phi 10$ & 0,048 & 0,146 & 0,057 & 0,043 & 0,146 & 0,183 & 1 & & & & & & & \\
\hline$\Phi 11$ & 0,065 & 0,062 & 0,043 & 0,168 & 0,138 & 0,063 & 0,157 & 1 & & & & & & \\
\hline$\Phi 12$ & 0,043 & 0,149 & 0,191 & 0,153 & 0,149 & 0,258 & 0,038 & 0,258 & 1 & & & & & \\
\hline$\Phi 13$ & 0,048 & 0,183 & 0,052 & 0,167 & 0,151 & 0,176 & 0,036 & 0,171 & 0,049 & 1 & & & & \\
\hline$\Phi 15$ & 0,036 & 0,172 & 0,164 & 0,048 & 0,177 & 0,023 & 0,237 & 0,258 & 0,161 & 0,051 & 1 & & & \\
\hline$\Phi 18$ & 0,052 & 0,176 & 0,048 & 0,151 & 0,056 & 0,064 & 0,147 & 0,251 & 0,142 & 0,036 & 0,172 & 1 & & \\
\hline$\Phi 20$ & 0,049 & 0,044 & 0,047 & 0,172 & 0,036 & 0,139 & 0,253 & 0,246 & 0,168 & 0,152 & 0,122 & 0,163 & 1 & \\
\hline$\Phi 24$ & 0,048 & 0,036 & 0,042 & 0,273 & 0,124 & 0,137 & 0,136 & 0,149 & 0,162 & 0,048 & 0,162 & 0,169 & 0,147 & 1 \\
\hline
\end{tabular}


расчета силы влияния факторов на принятие решения о выборе железнодорожной перевозки, задействованных в регрессионном анализе по следующей модели:

$Z_{i}=\beta_{0}+\beta_{1}{ }^{*} \mathrm{~T}_{i}+\beta_{2}{ }^{*} \mathrm{RK}_{i}+\beta_{3}{ }^{*} \mathrm{UR}_{i}+\beta_{4}{ }^{*} \mathrm{COST}_{i}+$ $\beta_{5}{ }^{*} \mathrm{C}_{i}+\beta_{6}{ }^{*} \mathrm{MARK}_{i}+\beta_{7}{ }^{*} \mathrm{TR}_{i}+\beta_{8}{ }^{*} \mathrm{GR}_{i}+\varepsilon_{i}$

где $Z_{i}$ - показатель приятия перевозки железнодорожным транспортом (бинарная переменная, где 1 - компания выбрала перевозку контейнеров железнодорожным транспортом; 0 - не выбрала),

$\mathrm{T}_{i}$ - тарифы на перевозку контейнеров,

$\mathrm{RK}_{i}$ - уровень пропускной способности существующей инфраструктуры,

$\mathrm{UR}_{i}-$ уровень согласованности сроков и стоимости грузоперевозок на территории России, осуществляемых различными участниками отрасли,

$\operatorname{COST}_{i}-$ расстояние, на которое будет осуществляться доставка,

$\mathrm{C}_{i}-$ наличие единого окна для грузоотправителя,

$\mathrm{MARK}_{i}$ - отслеживание груза,

$\mathrm{TR}_{i}$ - необходимость обеспечения особенных условий транспортировки груза,

$\mathrm{GR}_{i}-$ сохранность груза.

\section{Результаты исследования}

В Таблице 2 приведены результаты регрессионного анализа, которые позволяют рассмотреть влияние различных факторов на принятие решения о выборе способа перевозки железнодорожным транспортом. Нами была проведена оценка влияния этих независимых переменных на перевозку железнодорожным транспортом методом максимального правдоподобия. Следует отметить, что регрессионная модель позволила объяснить $63 \%$ вариации факторов в принятии железнодорожных перевозок.

При моделировании принятия решения о выборе способа перевозки железнодорожным транспортом компаниями оказалось, что расстояние, на которое будет осуществляться доставка $(\beta=0,264 ; \mathrm{p}<0,05)$, необходимость обеспечения особенных условий транспортировки груза $(\beta=0,451 ; p<0,10)$, сохранность груза $(\beta=$ $0,598 ; \mathrm{p}<0,10)$ позитивно влияют на принятие железнодорожных перевозок. Фактор «отслеживание груза» $(\beta=0,166 ; p=0,01)$ не оказывает значимого влияния на рост железнодорожных перевозок. А факторы «тарифы на перевозку контейнеров» $(\beta=-0,387 ; \mathrm{p}<0,10)$ оказывает отрицательное влияние на принятие решения об использовании железной дороги.

Наибольшее влияние оказывают факторы «тарифы на перевозку контейнеров», «уровень

Таблица 2. Факторы принятия решения о перевозки контейнеров железнодорожным транспортом

\begin{tabular}{|c|c|c|}
\hline Независимые показатели & \begin{tabular}{c|} 
Нестандарти- \\
зированные \\
коэффициенты
\end{tabular} & $\begin{array}{c}\text { Стандартизированные } \\
\text { коэффициенты }\end{array}$ \\
\hline Константа $\left(\beta_{0}\right)$ & $0,191(0,0134)$ & \\
\hline тарифы на перевозку контейнеров $\left(\mathrm{T}_{i}\right)$ & $0,564^{* * * * *}(0,098)$ & $0,581^{* * * * *}$ \\
\hline $\begin{array}{l}\text { уровень пропускной способности существующей инфраструкту- } \\
\text { ры }\left(\mathrm{RK}_{i}\right)\end{array}$ & $0,366^{* * * *}(0,015)$ & 0,385 \\
\hline $\begin{array}{l}\text { уровень согласованности сроков и стоимости грузоперевозок на } \\
\text { территории России, осуществляемых различными участниками } \\
\text { отрасли }\left(\mathrm{UR}_{i}\right)\end{array}$ & $0,451 * *(0,104)$ & $0,454^{* * *}$ \\
\hline расстояние, на которое будет осуществляться доставка $\left(\mathrm{COST}_{i}\right)$ & $0,298^{* * * * * *}(0,062)$ & $0,299 * * * *$ \\
\hline наличие единого окна для грузоотправителя $\left(\mathrm{C}_{i}\right)$ & $-0,287 * * * *(0,209)$ & $-0,285 * * *$ \\
\hline отслеживание груза $\left(\mathrm{EASE}_{i}\right)$ & $-0,196 * *(0,118)$ & $-0,394 * *$ \\
\hline $\begin{array}{l}\text { необходимость обеспечения особенных условий транспортиров- } \\
\text { ки груза }\left(\mathrm{TR}_{i}\right)\end{array}$ & $0,153 * * *(0,201)$ & $0,254 * * *$ \\
\hline сохранность груза $\left(\mathrm{GR}_{i}\right)$ & $-0,393 * * *(0,023)$ & $-0,194^{* * * * *}$ \\
\hline Скорректированный R -квадрат & \multicolumn{2}{|r|}{0,631} \\
\hline Количество наблюдений & \multicolumn{2}{|r|}{69} \\
\hline
\end{tabular}

*- значимость коэффициента $\mathrm{p}<0,10$; ** - значимость коэффициента $\mathrm{p}<0,05$;

*** - значимость коэффициента р < 0,01.

В скобках даны стандартные ошибки. 
пропускной способности существующей инфраструктуры», «уровень согласованности сроков и стоимости грузоперевозок на территории России, осуществляемых различными участниками отрасли» на рост железнодорожных перевозок.

Таким образом, результаты регрессионного анализа подтверждают значимость и достоверность представленной модели. Так, в соответствии с результатами анализа теоретической базы эмпирически было подтверждено, что при принятии компаниями решения о перевозке контейнеров железнодорожным транспортом наибольшее значение имели факторы «тарифы на перевозку контейнеров», «уровень пропускной способности существующей инфраструктуры», «уровень согласованности сроков и стоимости грузоперевозок на территории России, осуществляемых различными участниками отрасли». Большинство респондентов на качественном этапе исследования называли именно эти аспекты принятия в качестве наиболее важных.

Статья подготовлена по результатам исследований, выполненных за счет бюджетных средств по государственному заданию Финуниверситету.

\section{Библиографический список}

1. Feo M., Espino R., Garcia L. An stated preference analysis of Spanish freight forwarders modal choice on the southwest Europe Motorway of the Sea //Transport Policy.-2011.- T. 18. - № . 1.- C. 60-67.

2. Nam K. C. A study on the estimation and aggregation of disaggregate models of mode choice for freight transport //Transportation Research Part E: Logistics and Transportation Review. - 1997. - T. 33. - № . 3. - C. $223-231$.

3. Reis $V$. Analysis of mode choice variables in short-distance intermodal freight transport using an agent-based model //Transportation research part A: Policy and practice. - 2014. - T. 61.- C. 100-120.

4. Samimi A., Kawamura K., Mohammadian A. A behavioral analysis of freight mode choice decisions //Transportation planning and technology. - 2011.- T. 34. - № . 8. - C. 857-869.

5. Brooks M.R. et al. Understanding mode choice decisions: A study of Australian freight shippers //Maritime Economics \& Logistics. - 2012.- T. 14.- № . 3.- С. 274-299.

6. ЕY - «Обзор отрасли грузоперевозок в России». 2018. https://ru.investinrussia.com/data/file/ey-freighttransportation-survey-2018.pdf

7. Евразийский банк развития - «Транспортные коридоры шелкового пути: потенциал роста грузопотоков через ЕАЭС». 2018 https://eabr.org/upload/iblock/c2a/EDB-Centre_2018_Report-49_Transport-Corridors_RUS. pdf 